\title{
Tofacitinib, an Oral Janus Kinase Inhibitor: Pooled Efficacy and Safety Analyses in an Australian Rheumatoid Arthritis Population
}

\author{
Stephen Hall · Peter Nash • Maureen Rischmueller • David Bossingham • \\ Paul Bird · Nicola Cook · David Witcombe · Koshika Soma • \\ Kenneth Kwok · Krishan Thirunavukkarasu
}

Received: March 18, 2018 / Published online: June 11, 2018

(C) The Author(s) 2018

\begin{abstract}
Introduction: In Australia, there is an unmet need for improved treatments for rheumatoid arthritis (RA). Tofacitinib is an oral Janus kinase inhibitor for the treatment of RA. To provide an overview of key study outcomes for tofacitinib in Australian patients, we analyzed the efficacy and safety of tofacitinib in the Australian subpopulation of global RA phase III and long-term extension (LTE) studies.
\end{abstract}

Enhanced digital features To view enhanced digital features for this article go to https://doi.org/10.6084/ m9.figshare.6341663.

Electronic supplementary material The online version of this article (https://doi.org/10.1007/s40744018-0118-2) contains supplementary material, which is available to authorized users.

S. Hall

Department of Medicine, Cabrini Health and

Monash University, Emeritus Research, Melbourne, Australia

P. Nash

Department of Medicine, University of Queensland, Brisbane, Australia

M. Rischmueller

Department of Rheumatology, The Queen Elizabeth Hospital and University of Adelaide, Adelaide, Australia

D. Bossingham

Cairns Clinical School, James Cook University,

College of Medicine and Dentistry, Cairns, Australia
Methods: Data were pooled from the Australian subpopulation of four phase III studies and one LTE study (database not locked at cut-off date: January 2016). Patients in the phase III studies received tofacitinib 5 or $10 \mathrm{mg}$ twice daily (BID), placebo (advancing to tofacitinib at months 3 or 6), or adalimumab, with background methotrexate or conventional synthetic disease-modifying antirheumatic drugs. Patients in the LTE study received tofacitinib 5 or $10 \mathrm{mg}$ BID. Efficacy endpoints were American College of Rheumatology (ACR) 20/50/70 response rates, and change from baseline in the Disease Activity Score in 28 joints, erythrocyte sedimentation rate [DAS28-4(ESR)] and Health Assessment Questionnaire-Disability Index (HAQ-DI) scores. Safety endpoints included incidence of adverse events (AEs), serious AEs,

P. Bird

Faculty of Medicine, University of New South

Wales, Sydney, Australia

N. Cook

Department of Rheumatology, Royal Perth

Hospital, Perth, Australia

D. Witcombe $(\bowtie) \cdot K$. Thirunavukkarasu

Immunology and Inflammation, Pfizer Australia, Sydney, Australia

e-mail: david.witcombe@pfizer.com

K. Soma

Clinical Research, Pfizer Inc, Groton, CT, USA

K. Kwok

Biostatistics, Pfizer Inc, New York, NY, USA 
and discontinuations due to AEs. AEs of special interest and laboratory parameters were analyzed in the LTE study.

Results: Across phase III studies $(N=100)$, ACR response rates and improvements in DAS284(ESR) and HAQ-DI scores were numerically greater with tofacitinib vs. placebo at month 3 , and increased until month 12 . The results were sustained in the LTE study $(N=99)$ after 60 months' observation. In general, the efficacy and safety profiles of tofacitinib were similar to those of the global RA population.

Conclusions: In Australian patients with RA, tofacitinib therapy demonstrated sustained efficacy and consistent safety over $\geq 60$ months' treatment.

Funding: Pfizer Inc.

Trial registration numbers (all ClinicalTrials.gov): NCT00960440; NCT00847613; NCT00856544; NCT00853385; NCT00413699.

Keywords: Australia; Efficacy; Rheumatoid arthritis; Safety; Tofacitinib

\section{INTRODUCTION}

Rheumatoid arthritis (RA) is a chronic, systemic autoimmune disease characterized by persistent joint synovial tissue inflammation [1]. Uncontrolled RA is associated with reduced healthrelated quality of life (HRQoL) [2] and premature mortality $[3,4]$, and results in a substantial burden in terms of cost, disability, and loss of productivity [5]. Previous reports have estimated the prevalence of RA to be $0.6 \%$ in Australia [6] and 0.5\% in Australasia [7]; these are slightly higher than prevalence estimates for Western Europe (0.4\%), North America (0.4\%), and Southeast Asia (0.2\%) [7].

There also appears to be a considerable unmet need for improved disease control for patients with RA in Australia. The treat-to-target approach for RA aims to achieve clinical remission or low disease activity (LDA) and to maintain physical functioning and good quality of life [8]. Early treatment with disease-modifying antirheumatic drugs (DMARDs) is the recommended best-practice approach to disease management [8-11]. However, two studies of prescribing patterns in RA patients in Australian community-based practice have shown that disease activity remains inadequately controlled in a large proportion of patients, despite treatment with conventional synthetic DMARDS (csDMARDs) or biological DMARDS (bDMARDs); it was reported that over 39\% [12] and $47 \%$ [13] of patients receiving treatment for RA still experienced moderate to high disease activity. Treatment preference studies among patients with RA have shown that patients favor oral medications compared with subcutaneous (SC) self-injection and intravenous infusion [14, 15]; patient adherence and, consequently, treatment outcomes may be improved through the use of oral medications as opposed to SC or intravenous alternatives.

Tofacitinib is an oral Janus kinase inhibitor for the treatment of RA. The efficacy and safety of tofacitinib 5 and $10 \mathrm{mg}$ twice daily (BID), administered as monotherapy or in combination with csDMARDs [mainly methotrexate (MTX)], in patients with moderately to severely active RA, have been demonstrated in phase II [16-20] and phase III [21-26] randomized controlled trials of up to 24 months' duration, and in long-term extension (LTE) studies with up to 114 months of observation [27-29]. Tofacitinib was not available in Australia at the time of the two Australian real-world studies discussed above; however, it is now available for the treatment of the signs and symptoms of moderate-to-severe RA in adults who have had an inadequate response (IR) or are intolerant to MTX [30]. Tofacitinib may be used alone or in combination with csDMARDs, including MTX, at a recommended dose of $5 \mathrm{mg}$ BID.

Broadening our clinical understanding of treatments for RA in patients from Australia may improve the number of patients able to achieve remission or LDA. To provide an overview of key study outcomes for tofacitinib in Australian subjects, we pooled the efficacy and safety data for tofacitinib 5 and $10 \mathrm{mg}$ BID in the Australian subpopulation of the tofacitinib RA global phase III studies in csDMARD- or bDMARD-IR patients, and an LTE study including csDMARD-IR, bDMARD-IR, and MTXnaïve patients. 


\section{METHODS}

\section{Patients}

The efficacy and safety data included in these post hoc analyses were from the Australian subpopulation of four global tofacitinib RA phase III studies [ORAL Step (NCT00960440) [21]; ORAL Scan (NCT00847613) [25]; Oral Sync (NCT00856544) [23]; and ORAL Standard (NCT00853385) [26]] and one LTE study [ORAL Sequel (NCT00413699) [28]]. Full details of these studies, including patient inclusion and exclusion criteria, have been reported previously.

Eligible patients were aged $\geq 18$ years with moderately to severely active RA, based on the American College of Rheumatology (ACR) 1987 revised criteria. Patients enrolled in the phase III studies in this analysis had an IR to MTX (ORAL Scan, ORAL Standard), csDMARDs or bDMARDs (ORAL Sync), or tumor necrosis factor inhibitor therapy (ORAL Step). Patients enrolled in the LTE study had previously participated in a qualifying phase I, II, or III index study of tofacitinib. In the Australian subpopulation, patients entered the LTE from phase III studies only (phase I and II studies were not conducted in Australia), including those mentioned above, as well as ORAL Start, which included patients naïve to therapeutic doses of MTX [24].

\section{Studies}

The four phase III studies included in these analyses were randomized, double-blind, placebo-controlled clinical trials of $\geq 6$ months' duration $[21,23,25,26]$. Patients were randomized to receive tofacitinib 5 or $10 \mathrm{mg}$ BID or placebo with background MTX (ORAL Step, ORAL Scan, and ORAL Standard) or csDMARDs (ORAL Sync). ORAL Standard included an active control arm of adalimumab $40 \mathrm{mg}$ SC every other week $(\mathrm{Q} 2 \mathrm{~W})$ in patients receiving background MTX. In studies of $\geq 6$ months' duration (ORAL Scan, ORAL Sync, and ORAL Standard), patients receiving placebo were advanced to tofacitinib 5 or $10 \mathrm{mg}$ BID at month 3 (non-responding patients; patients who did not achieve $\geq 20 \%$ reduction from baseline in swollen and tender joint counts) or month 6 (all remaining placebo-treated patients). In ORAL Step (6 months' duration), all placebo patients were advanced to tofacitinib 5 or $10 \mathrm{mg}$ BID at month 3 on a blinded basis.

All Australian patients commenced treatment in the open-label LTE study with tofacitinib $10 \mathrm{mg}$ BID as monotherapy, or with background csDMARDs, according to their index study [28]. Doses of tofacitinib (5 or $10 \mathrm{mg}$ BID) or background medication in the LTE study could be adjusted according to the investigators' assessment of efficacy and safety.

All studies included in these analyses were conducted in compliance with the Declaration of Helsinki and the Good Clinical Practice Guidelines of the International Conference on Harmonisation, and were approved by the relevant Institutional Review Board and/or Independent Ethics Committee of the investigational centers. All patients provided written, informed consent.

\section{Analysis Populations}

Two datasets were included in the analysis: one for the phase III studies, which included up to 12 months of efficacy and safety data for Australian patients pooled from four phase III studies (ORAL Step, ORAL Scan, ORAL Sync, and ORAL Standard), and one for the LTE study, which included data for all Australian patients treated in ORAL Sequel.

The LTE study was ongoing at the time of analysis; data collection and analyses were continuing, and the study database was not yet locked (i.e., some values may change for the final, locked study database). LTE efficacy and safety data were included through 60 and 69 months of observation, respectively (data cut-off: January 14, 2016).

\section{Efficacy and Safety Analysis}

Efficacy was assessed every 3 months until month 12 in the phase III studies, and every 6 months until month 60 in the LTE study. The 
efficacy endpoints for both the phase III and LTE datasets included the proportions of patients achieving ACR20, ACR50, or ACR70 responses (defined as an improvement from baseline of at least 20, 50, and 70\%, respectively, in the number of tender and swollen joints and at least three of the five ACR components), and improvements from baseline in the Disease Activity Score in 28 joints using erythrocyte sedimentation rate [DAS28-4(ESR)] and Health Assessment Questionnaire-Disability Index (HAQ-DI). The proportions of patients achieving remission and LDA [DAS28-4(ESR) $<2.6$ and $\leq 3.2$, respectively) [31] were evaluated in the pooled phase III dataset, along with patient-reported outcomes. These included HRQoL evaluated using the Medical Outcomes Study Short Form-36 Health Survey [SF-36; including eight domains summarized into a physical component summary (PCS) score and a mental component summary (MCS) score], patient global assessment of disease activity (PtGA) recorded using a visual analog scale (VAS), patient global assessment of arthritis pain assessed utilizing a VAS, fatigue assessed using the Functional Assessment of Chronic Illness Therapy-Fatigue (FACIT-F), and sleep disturbance assessed using the Medical Outcomes Study sleep scale. The proportion of patients who achieved improvements greater than the minimum clinically important difference (MCID) in PtGA (10 points) [32], pain (10 points) [32], SF-36 PCS and MCS (2.5 points) $[32,33]$, and FACIT-F (4 points) [34] were also determined.

The safety analyses for both the pooled phase III dataset and the LTE study included the incidence of adverse events (AEs), serious AEs (SAEs), and discontinuations due to AEs. Additionally, several AEs of special interest were analyzed in the LTE study, including serious infection events (SIEs), all herpes zoster (HZ) events (serious and non-serious), nonmelanoma skin cancer (NMSC), all malignancies (excluding NMSC), melanoma, opportunistic infections [excluding tuberculosis (TB)], and major adverse cardiovascular events. The laboratory parameters analyzed for the LTE study were hemoglobin, absolute lymphocyte count (ALC), absolute neutrophil count (ANC), creatinine, high-density lipoprotein (HDL) and low-density lipoprotein (LDL) cholesterol, alanine aminotransferase (ALT), and aspartate aminotransferase (AST).

\section{Statistical Analysis}

All analyses were based on observed cases of the full analysis set, which included all patients who were randomized and received at least one dose of study treatment (tofacitinib, placebo, or adalimumab).

In the pooled phase III data analyses, the data are presented according to the study treatment received. The placebo groups in the phase III studies were combined up to month 3 , irrespective of the tofacitinib dose to which they were advanced. Numerical comparisons were made between the tofacitinib-treated and placebo-treated populations through month 3 , prior to advancement of the placebo group to tofacitinib.

For the LTE data analyses, the baseline was defined as that of the qualifying index study for patients who enrolled in the LTE study within 14 days of the final visit of the index study. If enrollment was $>14$ days after participation in the index study, the baseline was taken as the start of the LTE study. Assignment to the tofacitinib 5 or $10 \mathrm{mg}$ BID group in the LTE analysis was based on the calculation of the average total daily dose (TDD; sum of all doses received divided by the number of days of treatment) for each patient. Patients with TDD $<15 \mathrm{mg}$ were assigned to the $5 \mathrm{mg}$ BID group, while patients with $\mathrm{TDD} \geq 15 \mathrm{mg}$ were assigned to the $10 \mathrm{mg}$ BID group.

All analyses were descriptive in nature. As the studies were not powered to detect differences between treatment groups in this population, no statistical testing was performed.

\section{RESULTS}

\section{Patients}

Across the phase III studies, 100 Australian patients with RA were randomized to receive 
Table 1 Baseline demographics and disease characteristics of the Australian subpopulation (phase III and LTE studies)

\begin{tabular}{|c|c|c|c|c|c|c|}
\hline & \multicolumn{4}{|c|}{ Phase III studies $(N=100)$} & \multicolumn{2}{|c|}{ LTE study $(N=99)$} \\
\hline & $\begin{array}{l}\text { Tofacitinib } \\
5 \text { mg BID } \\
(N=33)\end{array}$ & $\begin{array}{l}\text { Tofacitinib } \\
10 \mathrm{mg} \text { BID } \\
(N=47)\end{array}$ & $\begin{array}{l}\text { Placebo } \\
(N=13)\end{array}$ & $\begin{array}{l}\text { Adalimumab } \\
40 \mathrm{mg} \text { Q2W } \\
(N=7)\end{array}$ & $\begin{array}{l}\text { Tofacitinib } \\
5 \mathrm{mg} \text { BID } \\
(N=2)\end{array}$ & $\begin{array}{l}\text { Tofacitinib } \\
10 \text { mg BID } \\
(N=97)\end{array}$ \\
\hline \multicolumn{7}{|c|}{ Baseline demographics } \\
\hline $\begin{array}{l}\text { Mean age }(\mathrm{SD}) \text {, } \\
\text { years }\end{array}$ & $58.8(10.9)$ & $54.3(10.7)$ & $51.3(15.3)$ & $56.7(11.3)$ & $55.5(2.1)$ & $56.6(12.0)$ \\
\hline Female, $n(\%)$ & $21(63.6)$ & $34(72.3)$ & $9(69.2)$ & $6(85.7)$ & $1(50.0)$ & $62(63.9)$ \\
\hline \multicolumn{7}{|l|}{ Race, $n(\%)$} \\
\hline White & $30(90.9)$ & $44(93.6)$ & $13(100.0)$ & $6(85.7)$ & $2(100.0)$ & $91(93.8)$ \\
\hline Asian & $1(3.0)$ & $2(4.3)$ & $0(0.0)$ & $0(0.0)$ & $0(0.0)$ & $2(2.1)$ \\
\hline Other & $2(6.1)$ & $1(2.1)$ & $0(0.0)$ & $1(14.3)$ & $0(0.0)$ & $4(4.1)$ \\
\hline \multicolumn{7}{|c|}{ Baseline disease characteristics } \\
\hline $\begin{array}{l}\text { Mean RA disease } \\
\text { duration } \\
\text { (range), years }\end{array}$ & $12.1(0.4-38.0)$ & $9.0(0.3-30.0)$ & $9.0(0.3-26.0)$ & $6.2(0.3-13.0)$ & & \\
\hline $\begin{array}{l}\text { RF positive, } \\
n(\%)\end{array}$ & $21(63.6)$ & $27(58.7)$ & $7(53.8)$ & $6(85.7)$ & & \\
\hline $\begin{array}{l}\text { Anti-CCP } \\
\text { positive, } n(\%)\end{array}$ & $22(66.7)$ & $26(56.5)^{\mathrm{a}}$ & $8(61.5)$ & $6(100.0)^{\mathrm{a}}$ & & \\
\hline Mean TJC (SD) & $26.4(16.3)$ & $25.1(16.2)$ & $26.9(18.0)$ & $28.6(13.5)$ & & \\
\hline Mean SJC (SD) & $18.4(10.4)$ & $14.5(6.8)$ & $20.2(11.6)$ & $18.0(8.3)$ & & \\
\hline $\begin{array}{l}\text { Mean DAS28- } \\
\text { 4(ESR) (SD) }\end{array}$ & $6.0(1.3)$ & $5.9(1.1)$ & $5.9(1.2)$ & $6.0(0.9)$ & $5.2(1.0)$ & $5.8(1.1)$ \\
\hline $\begin{array}{l}\text { Mean HAQ-DI } \\
\text { (SD) }\end{array}$ & $1.2(0.8)$ & $1.1(0.7)$ & $1.2(1.0)$ & $1.7(0.6)$ & $0.9(0.6)$ & $1.2(0.8)$ \\
\hline $\begin{array}{l}\text { Mean CRP (SD), } \\
\mathrm{mg} / \mathrm{l}\end{array}$ & $12.8(10.8)$ & $14.4(17.3)$ & $10.4(7.5)$ & $13.2(15.9)$ & & \\
\hline $\begin{array}{l}\text { Mean ESR (SD), } \\
\mathrm{mm} / \mathrm{h})\end{array}$ & $38.6(23.9)$ & $42.6(23.1)$ & $38.2(24.1)$ & $55.7(19.5)$ & & \\
\hline
\end{tabular}

$B I D$ twice daily, $C C P$ cyclic citrullinated peptide antibody, CRP C-reactive protein, DAS28-4(ESR) Disease Activity Score in 28 joints, erythrocyte sedimentation rate, HAQ-DI Health Assessment Questionnaire-Disability Index, LTE long-term extension, $Q 2 W$ every other week, $R A$ rheumatoid arthritis, $R F$ rheumatoid factor, $S D$ standard deviation, $S J C$ swollen joint count, TJC tender joint count

${ }^{\text {a }}$ For anti-CCP positive, $N=46$ for tofacitinib $10 \mathrm{mg}$ BID and $N=6$ for adalimumab $40 \mathrm{mg}$ Q2W

tofacitinib $5 \mathrm{mg}$ BID $(n=33)$, tofacitinib $10 \mathrm{mg}$ BID $(n=47)$, placebo $(n=13)$, or adalimumab $40 \mathrm{mg}$ Q2W $(n=7)$. The demographic and baseline disease characteristics are reported in Table 1. The majority of patients in the Australian population were female, with 


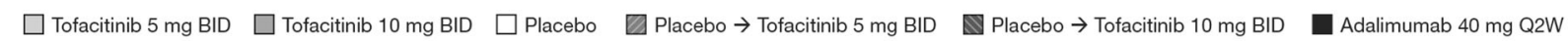

a

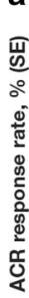

ACR20

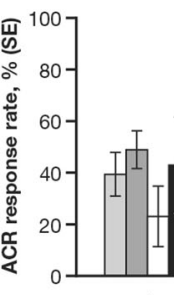

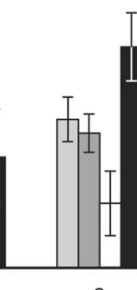

3

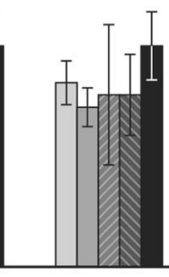

6

Month

b

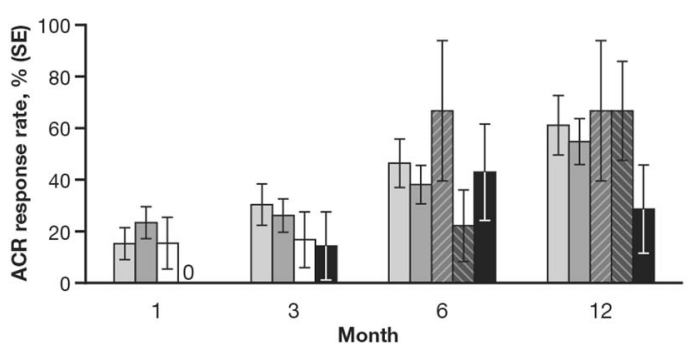

Tofacitinib $5 \mathrm{mg}$ BID, $N$ Tofacitinib $10 \mathrm{mg}$ BID, $N$ Placebo, $N$

Placebo $\rightarrow$ Tofacitinib $10 \mathrm{mg}$ BID, $N$

Adalimumab $40 \mathrm{mg} \mathrm{Q2W,} N$

\section{C}

ACR70

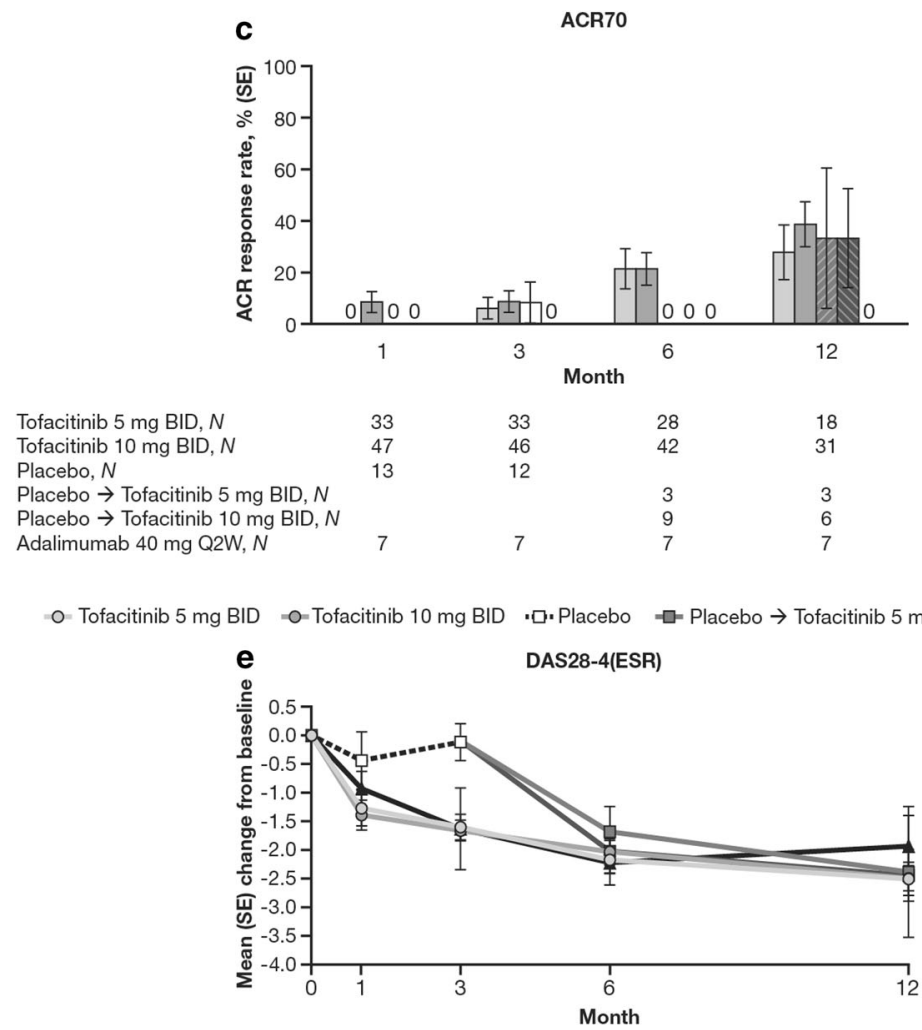

\section{d}

DAS28-4(ESR) at Month 12

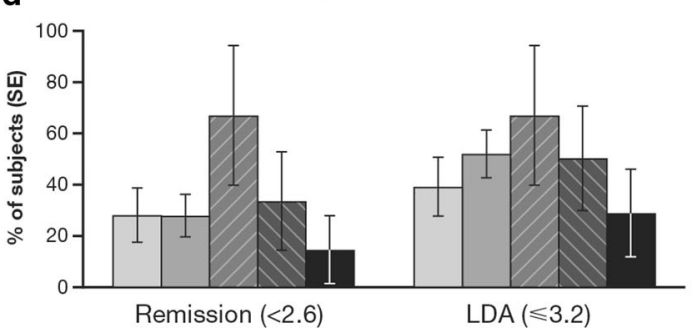

$N=\begin{array}{lllll}18 & 29 & 3 & 6 & 7\end{array}$

$\begin{array}{lllll}18 & 29 & 3 & 6 & 7\end{array}$

Tofacitinib $5 \mathrm{mg}$ BID $N$ Tofacitinib $10 \mathrm{mg}$ BID $N$ Placebo, $N$

Placebo $\rightarrow$ Tofacitinib $5 \mathrm{mg}$ BID, $N$

Placebo $\rightarrow$ Tofacitinib $10 \mathrm{mg}$ BID, $N$ Adalimumab $40 \mathrm{mg}$ Q2W, N

$\begin{array}{ccc}14 & 33 & 28 \\ 15 & 45 & 40 \\ 6 & 12 & 3 \\ & & 9 \\ 7 & 7 & 7\end{array}$
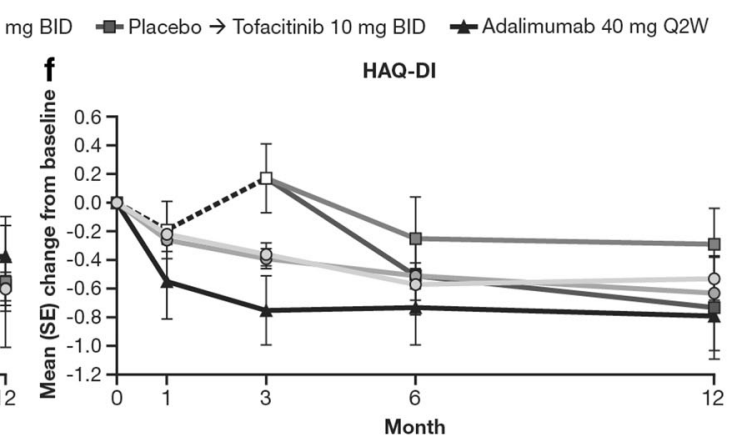
4Fig. 1 Efficacy over time in the pooled phase III study population, as measured by a ACR20 response rates, b ACR50 response rates, c ACR70 response rates, d proportion of patients achieving clinical remission and LDA at month 12, as measured by DAS28-4(ESR), e mean change from baseline in DAS28-4(ESR), and $\mathbf{f}$ mean change from baseline in HAQ-DI (FAS, no imputation). Remission was defined as DAS28-4(ESR) $<2$.6. LDA was defined as DAS28-4(ESR) $\leq 3.2$. ACR American College of Rheumatology, BID twice daily, DAS28-4(ESR) Disease Activity Score in 28 joints, erythrocyte sedimentation rate, FAS full analysis set, $H A Q-D I$ Health Assessment Questionnaire-Disability Index, $L D A$ low disease activity, $Q 2 W$ every other week, $S E$ standard error

established RA (mean disease duration $>6$ years in all treatment groups) and a high level of baseline disease activity [mean DAS28-4(ESR) $\geq 5.9$ in all treatment groups]. The majority of patients in each treatment group were Caucasian $(\geq 85.7 \%)$. Patients in the tofacitinib $5 \mathrm{mg}$ BID group had the longest mean disease duration (12.1 years); this was almost twice that of patients in the adalimumab group, though the smaller sample size must be taken into consideration.

The LTE study involved 99 Australian patients, with tofacitinib exposure of 322.5 patient-years. Two patients received an average TDD of tofacitinib $5 \mathrm{mg}$ BID; one discontinued treatment after month 3 due to insufficient clinical response. Data from the LTE study for patients receiving tofacitinib 5 and $10 \mathrm{mg}$ BID are presented together in these analyses, unless otherwise indicated.

\section{Efficacy}

In the phase III studies, patients receiving tofacitinib 5 and $10 \mathrm{mg}$ BID had numerically greater ACR20 response rates than those receiving placebo at months 1 and 3; ACR20 response rates increased to month 12 (Fig. 1a). The ACR50 response rates in the treatment groups also improved over time to month 12 (Fig. 1b). ACR70 response rates were either zero or low for all groups prior to month 3 , and increased over time until month 12 (Fig. 1c). By month 12, all placebo-treated patients had advanced to tofacitinib and achieved ACR20, ACR50, and ACR70 response rates similar to those of the tofacitinib-treated patients.

At month 12, a numerically higher proportion of patients who had received placebo and advanced to tofacitinib achieved clinical remission [DAS28-4(ESR) < 2.6] and LDA [DAS28-4(ESR) $\leq 3.2], \quad$ compared with tofacitinib-treated patients (Fig. 1d). Treatment with tofacitinib 5 and $10 \mathrm{mg}$ BID was associated with numerically greater improvement vs. placebo in DAS28-4(ESR) scores at months 1 and 3 (Fig. 1e); however, it must be noted that not all patients had DAS28-4(ESR) scores assessed at month 1 . The mean changes from baseline in DAS28-4(ESR) were similar for all groups at months 6 and 12, including the placebo-treated patients, once they had been advanced to tofacitinib; the numerically higher rates of remission and LDA in these patients may be due to low patient numbers compared with tofacitinib-treated patients.

HAQ-DI scores decreased from baseline through month 12, indicating improvement with active treatment (Fig. 1f). After month 6, improvement in HAQ-DI was also observed in patients who had advanced from placebo to tofacitinib.

Adalimumab resulted in similar ACR20 and lower ACR50 response rates vs. tofacitinib at Month 12; none of the seven patients receiving adalimumab achieved an ACR70 response (Fig. 1a-c). Additionally, although similar changes from baseline in DAS28-4(ESR) and HAQ-DI were observed with tofacitinib and adalimumab at month 12 (Fig. 1e-f), a numerically lower percentage of adalimumab-treated patients achieved remission and LDA vs. patients receiving tofacitinib (Fig. 1d).

Efficacy improvements with tofacitinib were sustained for up to 60 months of treatment in the LTE study (Fig. S1). In tofacitinib-treated patients, ACR response rates generally increased between month 1 and 60 (Fig. S1a). Mean improvements from baseline in DAS28-4(ESR) scores remained stable through month 60 in patients receiving tofacitinib (Fig. S1b). Mean HAQ-DI scores also improved from baseline, although a slight decrease in the change from 
baseline was observed at months 48 and 54 before increasing again at month 60 (Fig. S1c).

Analysis of PROs in the phase III Australian subpopulation showed that treatment with tofacitinib 5 and $10 \mathrm{mg}$ BID improved SF-36 scores, PtGA, pain, fatigue, and sleep disturbance. Consistent increases from baseline, indicating improvement, were seen in all eight domains of the SF-36 at month 3 with tofacitinib 5 and $10 \mathrm{mg}$ BID (Fig. 2a). SF-36 mean PCS and MCS improved from baseline to month 12 in patients treated with tofacitinib 5 and $10 \mathrm{mg}$ BID (Fig. 2b-c). There was a slight increase in PCS and MCS at month 1 in patients receiving placebo, but this was not sustained to month 3. Improvements from baseline PCS and MCS were observed at month 6 after patients switched from placebo to tofacitinib at either month 3 or 6 . Patients receiving adalimumab achieved greater changes from baseline in SF-36 social function, vitality, bodily pain, and general health domains at month 3 , and similar changes from baseline in PCS and MCS scores at month 12 compared with patients receiving tofacitinib (Fig. 2).

In the tofacitinib 5 and $10 \mathrm{mg}$ BID treatment groups, improvements in PtGA, pain, fatigue, and sleep disturbance scores were observed until month 12 (Figs. S2a-d). Similar improvements were observed in the placebo-treated patients after month 6 upon advancement to tofacitinib.

The seven patients receiving adalimumab appeared to experience similar improvements from baseline compared with tofacitinib through month 12 in all PROs except PtGA (Figs. S2a-d).

Furthermore, patients receiving tofacitinib 5 or $10 \mathrm{mg}$ BID were more likely to achieve clinically meaningful improvements for PtGA, pain, SF-36 PCS, and FACIT-F at month 1 and 3 (Table S1) vs. patients receiving placebo, as more patients reported improvements that were greater than the MCID.

\section{Safety}

During months $0-3$ of the phase III studies, the incidence of AEs was similar between the tofacitinib and placebo groups. The incidence of AEs in patients receiving tofacitinib 5 and $10 \mathrm{mg}$ BID was 78.8 and $72.3 \%$, respectively, at months 0-3, 51.4 and $48.1 \%$, respectively, at months 3-6, and 55.9 and $46.3 \%$, respectively, post-month 6 (Table 2). SAEs and discontinuations due to AEs occurred more frequently with tofacitinib vs. placebo until month 6 (Table 2).

Of the seven adalimumab-treated patients, four reported AEs at months $0-3$, two at months 3-6, and two post-month 6 . One patient reported an SAE at months 3-6. None of the patients receiving adalimumab discontinued due to AEs during the phase 3 studies (Table 2).

During the LTE study, SAEs were reported in $50(50.5 \%)$ tofacitinib-treated patients (Table 2). Overall, $53(53.5 \%)$ patients discontinued the study; 27 discontinued due to study drug-related AEs, while eight discontinued due to insufficient clinical response, including one patient receiving tofacitinib $5 \mathrm{mg}$ BID (data not shown).

Upper respiratory tract infection was the most frequently occurring $\mathrm{AE}$ in patients receiving tofacitinib 5 and $10 \mathrm{mg}$ BID during months $0-3$ (12.1 and $8.5 \%$, respectively), months 3-6 (5.4 and 9.3\%, respectively), and post-month 6 (8.8 and $18.5 \%$, respectively) of the phase III studies (Table 3 ). Upper respiratory tract infection was also the most commonly reported treatment-emergent AE during the LTE study (45.5\%) (Table 3$)$.

The AEs of special interest reported during the LTE study are listed in Table 3 . The most common AE of special interest was NMSC, followed by SIEs; these were reported in 22 [incidence rate: 7.8 (95\% confidence interval (CI) $4.9,11.9)$ ] and 21 [incidence rate: 6.6 (95\% CI $4.1,10.0)$ ] patients, respectively. HZ occurred in 18 (18.2\%) patients; three cases were serious and patients permanently discontinued treatment, and all except one non-serious case were resolved. Malignancies and opportunistic infections were each reported in four $(4.0 \%)$ patients during the LTE study (Table 3).

\section{Laboratory Parameters}

Selected laboratory parameters assessed during the LTE study are summarized in Fig. 3 and 

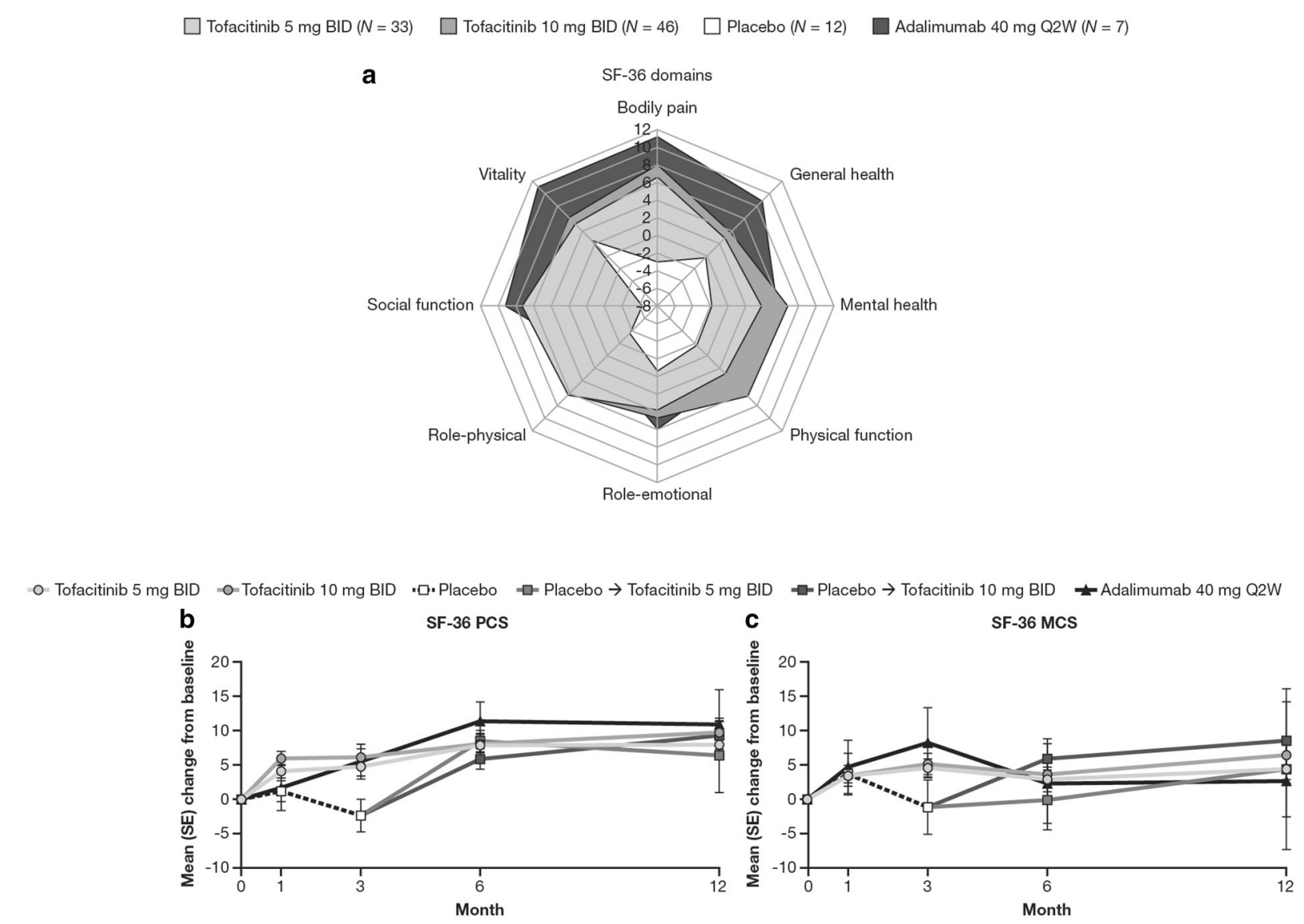

Tofacitinib $5 \mathrm{mg}$ BID, N

Tofacitinib $10 \mathrm{mg} \mathrm{BID,} N$

Placebo, $N$

Placebo $\rightarrow$ Tofacitinib $5 \mathrm{mg}$ BID, $N$

Placebo $\rightarrow$ Tofacitinib $10 \mathrm{mg}$ BID $N$

Adalimumab $40 \mathrm{mg}$ Q2W, $N$

Fig. 2 PROs in the pooled phase III study population showing the mean changes from baseline a across eight SF36 domain scores at month 3, b in SF-36 PCS to month 12 , and $\mathbf{c}$ in SF-36 MCS to month 12 (FAS, no imputation). BID twice daily, $F A S$ full analysis set, $M C S$

Table S2. Hemoglobin levels slightly decreased from baseline to month 30 with tofacitinib treatment, subsequently increased to month 48 , then decreased to month 60 (Fig. 3a). Mean ALC decreased through month 60 (Fig. 3b). The mean ANC somewhat decreased at month 1 and fluctuated throughout the LTE study, but by month 60 had returned to a similar level as month 1 (Fig. 3c). Mean creatinine levels increased from baseline at month 1 , and also fluctuated before returning to a level similar to month 1 by month 60 (Fig. 3d). HDL cholesterol levels increased from baseline at month 1 and remained stable, but LDL cholesterol levels initially increased to month 24, decreased at month 30 , then increased at month 36 before decreasing to below the baseline value at month 60 (Fig. 3e). A summary of abnormal laboratory observations meeting protocol for monitoring or discontinuation is provided in Table $\mathrm{S} 2$. The proportions of patients receiving tofacitinib who had confirmed decreases in hemoglobin, neutrophil count, and lymphocyte count, and increases in AST and/or 
Table 2 Summary of AEs, discontinuations due to AEs, SAEs, and AEs of special interest during the phase III studies and the LTE

\begin{tabular}{|c|c|c|c|c|}
\hline & $\begin{array}{l}\text { Tofacitinib } \\
5 \mathrm{mg} \text { BID }\end{array}$ & $\begin{array}{l}\text { Tofacitinib } \\
10 \mathrm{mg} \text { BID }\end{array}$ & Placebo & $\begin{array}{l}\text { Adalimumab } \\
\mathbf{4 0} \mathrm{mg} \mathrm{Q} \mathbf{2 W}\end{array}$ \\
\hline \multicolumn{5}{|l|}{ Months $0-3$} \\
\hline Subjects evaluable for AEs, $N$ & 33 & 47 & 13 & 7 \\
\hline Subjects with AEs, $n$ (\%) & $26(78.8)$ & $34(72.3)$ & $10(76.9)$ & $4(57.1)$ \\
\hline Subjects with SAEs, $n(\%)$ & $2(6.1)$ & $3(6.4)$ & $0(0.0)$ & $0(0.0)$ \\
\hline Discontinuations due to AEs, $n(\%)$ & $1(3.0)$ & $1(2.1)$ & $0(0.0)$ & $0(0.0)$ \\
\hline \multicolumn{5}{|l|}{ Months $3-6^{a}$} \\
\hline Subjects evaluable for AEs, $N$ & 37 & 54 & 2 & 7 \\
\hline Subjects with AEs, $n$ (\%) & $19(51.4)$ & $26(48.1)$ & $2(100.0)$ & $2(28.6)$ \\
\hline Subjects with SAEs, $n$ (\%) & $4(10.8)$ & $1(1.9)$ & $0(0.0)$ & $1(14.3)$ \\
\hline Discontinuations due to AEs, $n(\%)$ & $3(8.1)$ & $2(3.7)$ & $0(0.0)$ & $0(0.0)$ \\
\hline \multicolumn{5}{|l|}{ Post-month $6^{\mathrm{a}}$} \\
\hline Subjects evaluable for AEs, $N$ & 34 & 54 & 0 & 7 \\
\hline Subjects with AEs, $n$ (\%) & $19(55.9)$ & $25(46.3)$ & $\mathrm{N} / \mathrm{A}$ & $2(28.6)$ \\
\hline Subjects with SAEs, $n(\%)$ & $1(2.9)$ & $5(9.3)$ & $\mathrm{N} / \mathrm{A}$ & $0(0.0)$ \\
\hline Discontinuations due to AEs, $n$ (\%) & $0(0.0)$ & $2(3.7)$ & $\mathrm{N} / \mathrm{A}$ & $0(0.0)$ \\
\hline \multicolumn{5}{|l|}{ LTE study ${ }^{\mathrm{b}}$} \\
\hline Subjects evaluable for AEs, $N$ & & 99 & & \\
\hline Subjects with AEs, $n(\%)$ & & $96(97.0)$ & & \\
\hline Subjects with SAEs, $n(\%)$ & & $50(50.5)$ & & \\
\hline Discontinuations due to AEs, $n$ (\%) & & $33(33.3)$ & & \\
\hline
\end{tabular}

$A E$ adverse event, $B I D$ twice daily, $L T E$ long-term extension, $N / A$ not applicable, $Q 2 W$ every other week, $S A E$ serious adverse event, $T D D$ total daily dose

a Tofacitinib groups included patients initially receiving placebo who had advanced at month 3 or month 6

${ }^{\mathrm{b}}$ Includes patients receiving a TDD of tofacitinib $5 \mathrm{mg} \operatorname{BID}(n=2)$ and $10 \mathrm{mg}$ BID $(n=97)$. One patient receiving tofacitinib $5 \mathrm{mg}$ BID discontinued treatment after month 3

ALT levels, and serum creatinine, was $\leq 5.1 \%$ for each measurement.

\section{DISCUSSION}

These post hoc analyses demonstrated the efficacy and safety of tofacitinib 5 and $10 \mathrm{mg}$ BID in combination with MTX or csDMARDs in reducing signs and symptoms of RA and improving physical function in the Australian subpopulation of patients participating in the global tofacitinib RA development program.

Across phase III studies, ACR response rates and improvements in mean DAS28-4(ESR) and mean HAQ-DI were observed at month 1 and continued to increase throughout 12 months' 
Table 3 Summary of the most commonly reported AEs ( $\geq 5 \%$ in any tofacitinib group) during the phase III studies and the LTE study, and AEs of special interest during the LTE study

\begin{tabular}{|c|c|c|c|c|}
\hline & $\begin{array}{l}\text { Tofacitinib } \\
5 \text { mg BID }\end{array}$ & $\begin{array}{l}\text { Tofacitinib } \\
10 \mathrm{mg} \text { BID }\end{array}$ & Placebo & $\begin{array}{l}\text { Adalimumab } \\
40 \mathrm{mg} \mathrm{Q} 2 \mathrm{~W}\end{array}$ \\
\hline Months $0-3, n(\%)$ & $(N=33)$ & $(N=47)$ & $(N=13)$ & $(N=7)$ \\
\hline Upper respiratory tract infection & $4(12.1)$ & $4(8.5)$ & $0(0.0)$ & $1(14.3)$ \\
\hline Urinary tract infection & $3(9.1)$ & $1(2.1)$ & $1(7.7)$ & $1(14.3)$ \\
\hline Nausea & $2(6.1)$ & $3(6.4)$ & $1(7.7)$ & $0(0.0)$ \\
\hline Diarrhea & $2(6.1)$ & $1(2.1)$ & $2(15.4)$ & $0(0.0)$ \\
\hline Back pain & $2(6.1)$ & $1(2.1)$ & $0(0.0)$ & $0(0.0)$ \\
\hline Headache & $2(6.1)$ & $0(0.0)$ & $2(15.4)$ & $0(0.0)$ \\
\hline Mouth ulceration & $2(6.1)$ & $0(0.0)$ & $1(7.7)$ & $0(0.0)$ \\
\hline Lower respiratory tract infection & $1(3.0)$ & $4(8.5)$ & $0(0.0)$ & $0(0.0)$ \\
\hline Incorrect dose administered & $0(0.0)$ & $4(8.5)$ & $1(7.7)$ & $0(0.0)$ \\
\hline Rash & $0(0.0)$ & $3(6.4)$ & $0(0.0)$ & $0(0.0)$ \\
\hline Months 3-6, ${ }^{\mathrm{a}}$ (\%) & $(N=37)$ & $(N=54)$ & $(N=2)$ & $(N=7)$ \\
\hline Upper respiratory tract infection & $2(5.4)$ & $5(9.3)$ & $0(0.0)$ & $0(0.0)$ \\
\hline Urinary tract infection & $3(8.1)$ & $3(5.6)$ & $0(0.0)$ & $1(14.3)$ \\
\hline Fall & $2(5.4)$ & $2(3.7)$ & $0(0.0)$ & $0(0.0)$ \\
\hline Arthralgia & $2(5.4)$ & $1(1.9)$ & $0(0.0)$ & $0(0.0)$ \\
\hline Back pain & $2(5.4)$ & $0(0.0)$ & $1(50.0)$ & $0(0.0)$ \\
\hline Rash & $2(5.4)$ & $0(0.0)$ & $0(0.0)$ & $0(0.0)$ \\
\hline Nausea & $0(0.0)$ & $3(5.6)$ & $0(0.0)$ & $0(0.0)$ \\
\hline Vomiting & $0(0.0)$ & $3(5.6)$ & $0(0.0)$ & $0(0.0)$ \\
\hline Post-month $6,{ }^{\mathrm{a}} n(\%)$ & $(N=34)$ & $(N=54)$ & $(N=0)$ & $(N=7)$ \\
\hline Upper respiratory tract infection & $3(8.8)$ & $10(18.5)$ & $\mathrm{N} / \mathrm{A}$ & $1(14.3)$ \\
\hline Lower respiratory tract infection & $2(5.9)$ & $6(11.1)$ & $\mathrm{N} / \mathrm{A}$ & $0(0.0)$ \\
\hline Sinusitis & $4(11.8)$ & $0(0.0)$ & $\mathrm{N} / \mathrm{A}$ & $0(0.0)$ \\
\hline Hypertension & $2(5.9)$ & $2(3.7)$ & $\mathrm{N} / \mathrm{A}$ & $0(0.0)$ \\
\hline Fall & $2(5.9)$ & $2(3.7)$ & $\mathrm{N} / \mathrm{A}$ & $0(0.0)$ \\
\hline Pneumonia & $2(5.9)$ & $1(1.9)$ & $\mathrm{N} / \mathrm{A}$ & $0(0.0)$ \\
\hline Atypical fibroxanthoma & $2(5.9)$ & $0(0.0)$ & $\mathrm{N} / \mathrm{A}$ & $0(0.0)$ \\
\hline Cataract & $2(5.9)$ & $0(0.0)$ & $\mathrm{N} / \mathrm{A}$ & $0(0.0)$ \\
\hline Tinea pedis & $2(5.9)$ & $0(0.0)$ & N/A & $0(0.0)$ \\
\hline Urinary tract infection & $1(2.9)$ & $3(5.6)$ & $\mathrm{N} / \mathrm{A}$ & $0(0.0)$ \\
\hline
\end{tabular}


Table 3 continued

\begin{tabular}{|c|c|c|c|c|}
\hline & $\begin{array}{l}\text { Tofacitinib } \\
5 \mathrm{mg} \mathrm{BID}\end{array}$ & $\begin{array}{l}\text { Tofacitinib } \\
10 \mathrm{mg} \text { BID }\end{array}$ & Placebo & $\begin{array}{l}\text { Adalimumab } \\
40 \mathrm{mg} \mathrm{Q} 2 \mathrm{~W}\end{array}$ \\
\hline LTE study, ${ }^{\mathrm{b}} n(\%)$ & & $(N=99)$ & & \\
\hline Upper respiratory tract infection & & $45(45.5)$ & & \\
\hline Lower respiratory tract infection & & $22(22.2)$ & & \\
\hline Urinary tract infection & & $19(19.2)$ & & \\
\hline $\mathrm{HZ}^{\mathrm{c}}$ & & $18(18.2)$ & & \\
\hline Basal cell carcinoma & & $13(13.1)$ & & \\
\hline Fall & & $12(12.1)$ & & \\
\hline Pneumonia & & $11(11.1)$ & & \\
\hline Arthralgia & & $10(10.1)$ & & \\
\hline Actinic keratosis & & $10(10.1)$ & & \\
\hline Skin lesion & & $10(10.1)$ & & \\
\hline Diarrhea & & $9(9.1)$ & & \\
\hline Squamous cell carcinoma & & $9(9.1)$ & & \\
\hline Nausea & & $8(8.1)$ & & \\
\hline Gastroenteritis & & $8(8.1)$ & & \\
\hline Pain in extremity & & $8(8.1)$ & & \\
\hline Back pain & & $8(8.1)$ & & \\
\hline Vitamin D deficiency & & $7(7.1)$ & & \\
\hline Laceration & & $7(7.1)$ & & \\
\hline Bursitis & & $7(7.1)$ & & \\
\hline Bowen's disease & & $7(7.1)$ & & \\
\hline Rash & & $7(7.1)$ & & \\
\hline Hypertension & & $7(7.1)$ & & \\
\hline Respiratory tract infection & & $6(6.1)$ & & \\
\hline Neck pain & & $6(6.1)$ & & \\
\hline Anemia & & $5(5.1)$ & & \\
\hline Cataract & & $5(5.1)$ & & \\
\hline Gastroesophageal reflux disease & & $5(5.1)$ & & \\
\hline Bronchitis & & $5(5.1)$ & & \\
\hline Tooth abscess & & $5(5.1)$ & & \\
\hline Skin papilloma & & $5(5.1)$ & & \\
\hline Influenza & & $5(5.1)$ & & \\
\hline
\end{tabular}


Table 3 continued

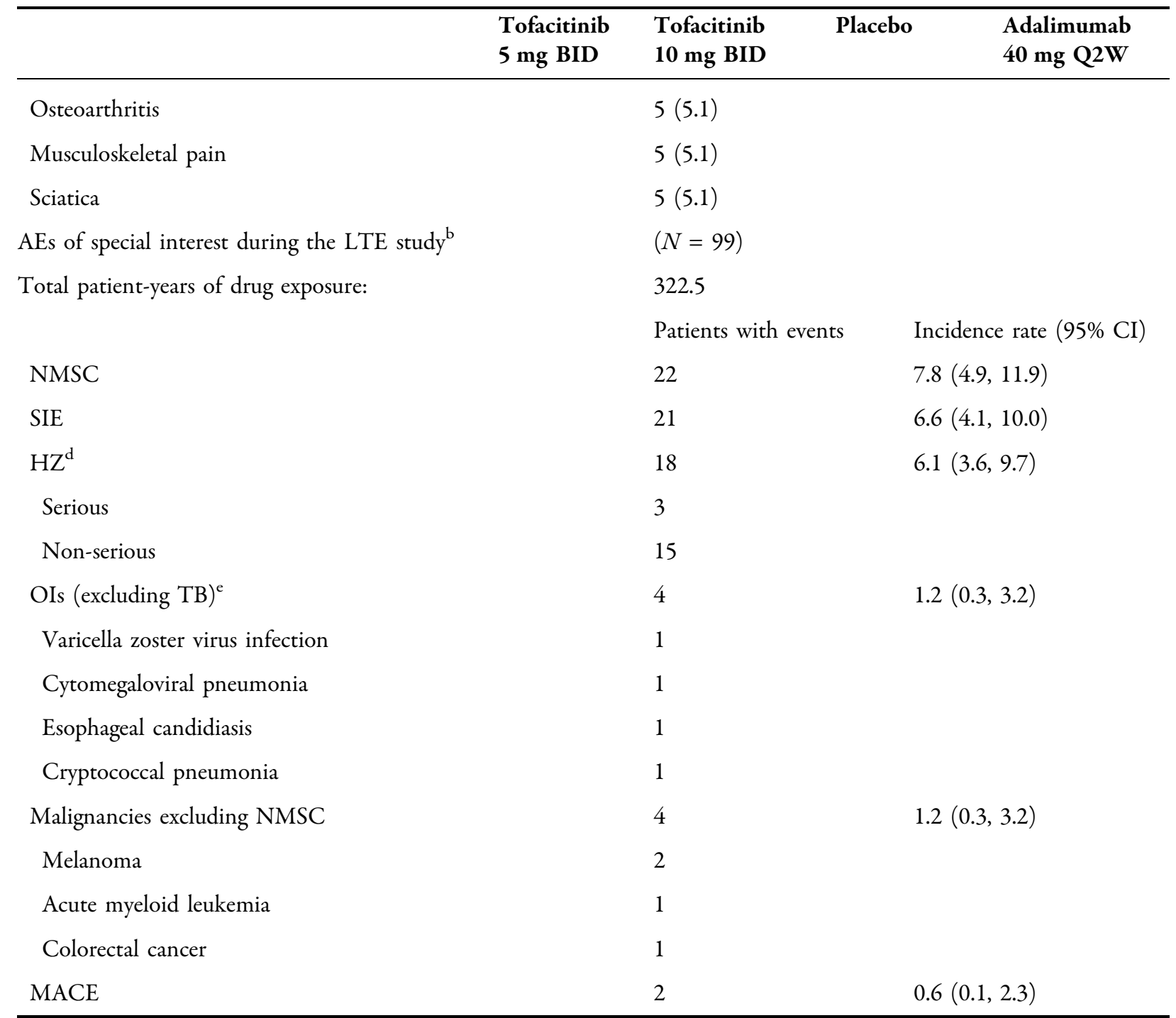

$A E$ adverse event, $B I D$ twice daily, $C I$ confidence interval, $H Z$ herpes zoster, $L T E$ long-term extension, $M A C E$ major adverse cardiovascular events, $N / A$ not applicable, $N M S C$ non-melanoma skin cancer, $O I$ opportunistic infection, $Q 2 W$ every other week, $S I E$ serious infection event, $T B$ tuberculosis, $T D D$ total daily dose

a Tofacitinib groups included patients initially receiving placebo who had advanced at months 3 or 6

b Includes patients receiving a TDD of tofacitinib $5 \mathrm{mg}$ BID $(n=2)$ and tofacitinib $10 \mathrm{mg}$ BID $(n=97)$. One patient receiving tofacitinib $5 \mathrm{mg}$ BID discontinued treatment after month 3

c Includes a collection of $\mathrm{HZ}$ terms

d All cases of HZ were resolved except one

e All cases of OI were resolved

treatment with tofacitinib. These efficacy improvements with tofacitinib were maintained during the LTE study (up to 60 months' treatment); however, it must be noted that patient numbers decreased throughout the LTE study due to discontinuations of treatment, or as some patients had not yet reached the later assessment time points by the time of the data cut for this analysis. 

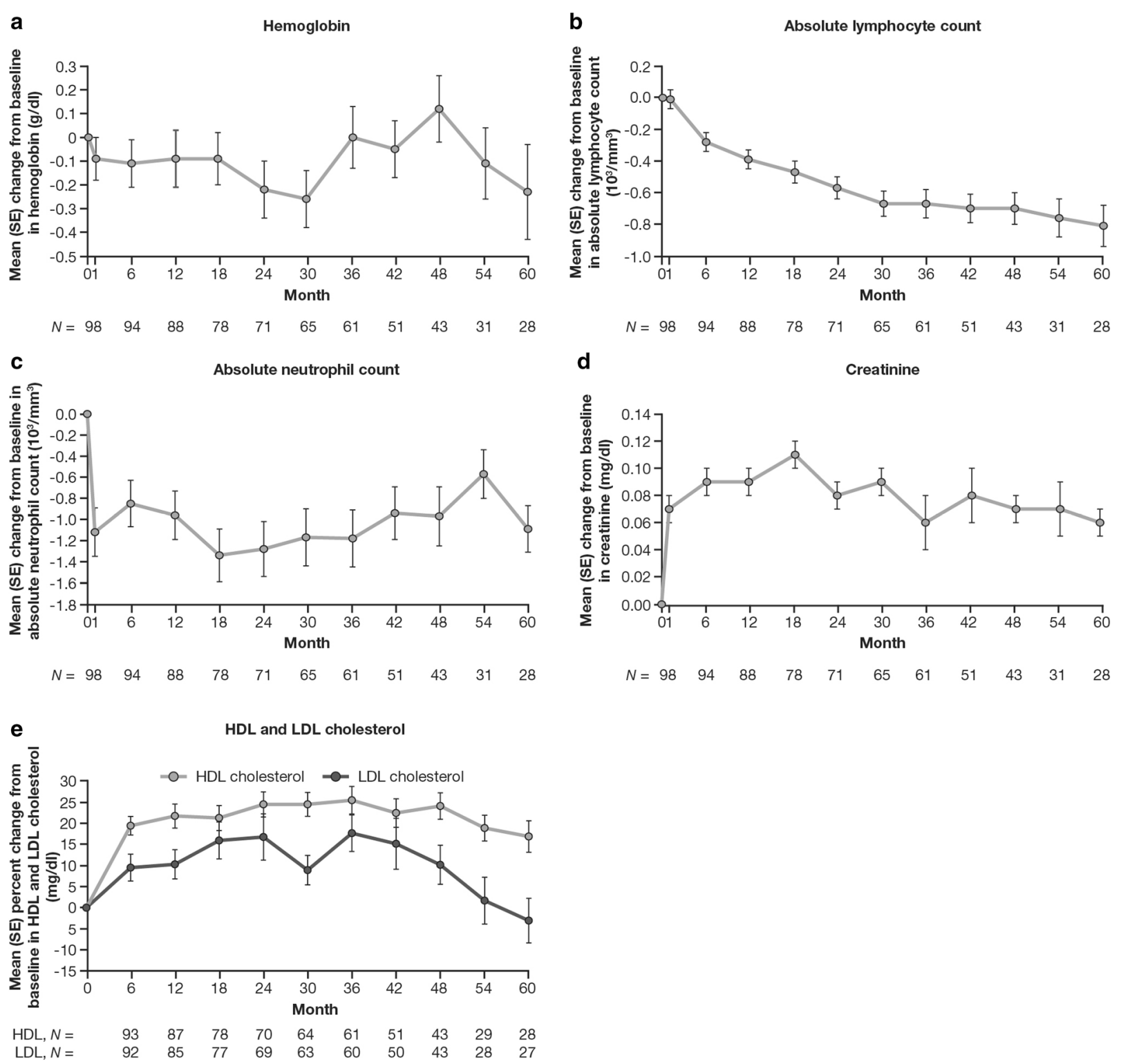

${ }^{a}$ Data were pooled for patients receiving a TDD of tofacitinib $5 \mathrm{mg} \mathrm{BID}(n=2)$ and $10 \mathrm{mg} \operatorname{BID}(n=97)$. One patient receiving tofacitinib $5 \mathrm{mg}$ BID discontinued treatment after month 3

Fig. 3 Summary of changes in laboratory variables following treatment with tofacitinib ${ }^{a}$ during the LTE study, showing mean change from baseline in a hemoglobin $(\mathrm{g} / \mathrm{dl})$, b absolute lymphocyte count $\left(10^{9}\right.$ cells/l), c absolute neutrophil count $\left(10^{9}\right.$ cells $\left./ \mathrm{l}\right)$, $\mathbf{d}$ serum creatinine $(\mathrm{mg} / \mathrm{dl})$, and

In general, the efficacy and safety profiles of tofacitinib observed in the Australian subpopulation were similar to those reported previously for the global RA tofacitinib population $[21,23,25,26,29]$. Australian patients had e HDL and LDL cholesterol (percent change). BID twice daily, $H D L$ high-density lipoprotein, $L D L$ low-density lipoprotein, $L T E$ long-term extension, $S E$ standard error, $T D D$ total daily dose

numerically higher rates of ACR20 response and DAS28-4(ESR)-defined remission than the global population (inclusive of Australian patients) in the phase III tofacitinib studies at month 6 [ACR20: 71.4 and 61.9\% (Australian cohort) vs. 
51.1-52.1 and 52.6-61.8\% (global phase III studies); remission: 21.4 and $22.5 \%$ (Australian cohort) vs. 6.2-10.7 and 12.5-16.0\% (global phase III studies) for tofacitinib 5 and $10 \mathrm{mg}$ BID, respectively] [21, 23, 25, 26].

Our analysis also suggested that treatment with tofacitinib 5 and $10 \mathrm{mg}$ BID reduced the broad burden of active RA in the Australian subpopulation of patients from the phase III RA studies. Treatment with tofacitinib for 3 months resulted in clinically meaningful improvements, indicated by the changes from baseline greater than the MCID, across multiple PROs, consistent with the primary efficacy findings.

Tofacitinib demonstrated a consistent safety profile in both the phase III and LTE studies, with no new safety signals detected through 69 months' observation in the LTE study. In the LTE study, a higher percentage of Australian patients experienced SAEs (50.5 vs. 29.4\%) and discontinued the study due to AEs (33.3 vs. $23.9 \%$ ) compared with the combined global and Japanese LTE population [29]. The differences in the Australian population are unexplained; however, the number of patient-years of exposure for tofacitinib $10 \mathrm{mg}$ BID in the Australian subpopulation (322.5 patient-years) was $<2 \%$ of that of the global and Japanese LTE study population $(17,738.5$ patient-years) [29], which may account for the discrepancies in the results. Additionally, incidence rates (95\% CI) of NMSC were higher in the tofacitinib-treated Australian LTE subpopulation $[7.8(4.9,11.9)]$ compared with the tofacitinib-treated global LTE and global phase I, II, III, and LTE populations [0.64 (0.50-0.81) and $0.55(0.45-0.69)$, respectively] [35]. This may also be due to the small numbers of patients in the studies (99 vs. 4847 and 6092, respectively); however, the high levels of sun exposure in Australia may potentially contribute to the higher rates of NMSC in this population, as well as the high diagnosis rate for such lesions in Australia [36, 37]. Furthermore, the history of NMSC in these patients is not known; the risk of developing NMSC is higher in patients who have previously had NMSC [38]. Further research is needed on the incidence of NMSC in tofacitinib-treated patients in populations with high sun exposure. Incidence rates $(95 \% \mathrm{CI})$ of $\mathrm{HZ}$ and opportunistic infections (excluding TB) were higher in the Australian LTE subpopulation, compared with an analysis of tofacitinib global phase I, II, III, and LTE data $[6.1(3.6,9.7)$ vs. $3.9(3.6-4.2)$ and $1.2(0.3,3.2)$ vs. $0.3(0.2-0.4)$, respectively] [39]. Finally, the mean overall values for laboratory safety parameters in the Australian subpopulation also demonstrated variability compared with the global and Japanese populations, again likely due to the limited number of patients. Although the mean changes from baseline in ANC were similar to those of the global phase III and LTE population, the mean ALC in the Australian subpopulation showed a greater decrease from baseline compared with the global population [40] and appeared to decrease through month 60 . This may also be a consequence of the smaller number of patients in the Australian subpopulation, as it is also in contrast to the larger global population, from which a pooled analysis of six phase III RCTs and two LTE studies indicated that lymphocyte count decreases stabilized at approximately month 48 [40]. Hemoglobin levels also decreased in the Australian subpopulation; this is in contrast to the global population, in which hemoglobin levels generally tended to increase $[28,40]$.

A general limitation of this study is that the analyses were post hoc, and due to small sample sizes and the short duration of exposure to placebo or adalimumab in the phase III studies, no statistical analyses were performed to compare safety or efficacy between treatment groups. Furthermore, there was no batch randomization by country to ensure the even distribution of patients to each treatment group within a country, which may have resulted in an imbalance between treatment groups and low numbers in some groups. Additionally, the pooling of the data from four phase III studies with different designs and methodology may have led to a heterogeneous patient population. Australia is an ethnically diverse country, which overall has a Caucasian population of approximately 75\% [41]; this should be taken into account when considering the wider applicability of these data from an analysis where $\geq 93 \%$ of all patients were Caucasian. 
LTE studies involve a highly selected patient population who have successfully completed the preceding index studies, and in whom the study drug is known to be efficacious and well tolerated. Thus, the design can overestimate benefit and underestimate harm [28]. Another drawback of such studies is that both patient and disease states may change over time, and that progressively smaller patient numbers over time, as treatment is discontinued, may influence efficacy and safety results.

Finally, it should also be noted that in the LTE study reported in this analysis, the majority of patients received a TDD of tofacitinib $10 \mathrm{mg}$ BID $(n=97)$, with two patients receiving tofacitinib $5 \mathrm{mg}$ BID; therefore, the efficacy and safety data reported here for this study do not correspond to the licensed dose of tofacitinib (5 mg BID) in Australia, as well as that in most countries where tofacitinib has received marketing approval.

\section{CONCLUSIONS}

In phase III and LTE studies involving Australian patients with RA, tofacitinib therapy with background MTX or csDMARDs demonstrated sustained efficacy for up to 60 months' treatment, and was consistent with results reported previously for the global population. Although higher rates of AEs were observed compared with the global population, tofacitinib generally had a consistent safety profile with no new safety signals for up to 69 months of treatment.

\section{ACKNOWLEDGEMENTS}

We wish to thank all patients who participated in these trials, as well as investigators and staff of the participating centers.

Funding. These studies, editorial support, and the journal's article processing charges were sponsored by Pfizer Inc, New York, NY, USA. All authors had full access to all of the data in this study and take complete responsibility for the integrity of the data and accuracy of the data analysis.

Medical Writing and/or Editorial Assistance. Medical writing support, under the guidance of the authors, was provided by Christina Viegelmann, PhD, at CMC Connect, a division of Complete Medical Communications Ltd, Glasgow, UK and was funded by Pfizer Inc, New York, NY, USA in accordance with Good Publication Practice (GPP3) guidelines (Ann Intern Med. 2015;163:461-4).

Authorship. All named authors meet the International Committee of Medical Journal Editors (ICMJE) criteria for authorship for this manuscript, take responsibility for the integrity of the work as a whole, and have given final approval to the version to be submitted.

Prior Presentation. Some of the data in this manuscript have previously been presented at the Australian Rheumatology Association 53rd Annual Scientific Meeting (12-15 May 2012, Canberra, Australia), the Australian Rheumatology Association 54th Annual Scientific Meeting (18-22 May 2013, Perth, Australia), and the Australian Rheumatology Association 55th Annual Scientific meeting (17-20 May 2014, Hobart, Tasmania, Australia).

Disclosures. Stephen Hall has received grants for research and clinical trials and honoraria for advice and lectures on behalf of Pfizer Inc. Peter Nash has received grants for research and clinical trials and honoraria for advice and lectures on behalf of Pfizer Inc. Maureen Rischmueller has received honoraria for advice and lectures on behalf of Pfizer Inc. David Bossingham has received honoraria for advice and lectures on behalf of Pfizer Inc. Paul Bird has received grants for research and clinical trials and honoraria for advice and lectures on behalf of Pfizer Inc. Nicola Cook has received honoraria for advice and lectures on behalf of Pfizer Inc. David Witcombe is an employee and shareholder of Pfizer Inc. Koshika Soma is an employee and shareholder of Pfizer Inc Kenneth Kwok is an employee and shareholder 
of Pfizer Inc. Krishan Thirunavukkarasu is an employee and shareholder of Pfizer Inc.

Compliance with Ethics Guidelines. All studies included in these analyses were conducted in compliance with the Declaration of Helsinki and the Good Clinical Practice Guidelines of the International Conference on Harmonisation, and were approved by the relevant Institutional Review Board and/or Independent Ethics Committee of the investigational centers. All patients provided written, informed consent.

Data Availability. The datasets generated during and/or analyzed during the studies are available from the corresponding author on reasonable request.

Open Access. This article is distributed under the terms of the Creative Commons Attribution-NonCommercial 4.0 International License (http://creativecommons.org/licenses/ by-nc/4.0/), which permits any noncommercial use, distribution, and reproduction in any medium, provided you give appropriate credit to the original author(s) and the source, provide a link to the Creative Commons license, and indicate if changes were made.

\section{REFERENCES}

1. Smolen JS, Aletaha D, McInnes IB. Rheumatoid arthritis. Lancet. 2016;388:2023-38.

2. Strand V, Singh JA. Newer biological agents in rheumatoid arthritis: impact on health-related quality of life and productivity. Drugs. 2010;70:121-45.

3. Lassere MN, Rappo J, Portek IJ, Sturgess A, Edmonds JP. How many life years are lost in patients with rheumatoid arthritis? Secular cause-specific and allcause mortality in rheumatoid arthritis, and their predictors in a long-term Australian cohort study. Intern Med J. 2013;43:66-72.

4. van den Hoek J, Boshuizen HC, Roorda LD, et al. Mortality in patients with rheumatoid arthritis: a 15-year prospective cohort study. Rheumatol Int. 2017;37:487-93.
5. Strand V, Khanna D. The impact of rheumatoid arthritis and treatment on patients' lives. Clin Exp Rheumatol. 2010;28:S32-40.

6. Harrison C, Britt H, Miller G, Henderson J. Prevalence of chronic conditions in Australia. PLoS One. 2013;8:e67494.

7. Cross M, Smith E, Hoy D, et al. The global burden of rheumatoid arthritis: estimates from the global burden of disease 2010 study. Ann Rheum Dis. 2014;73:1316-22.

8. Lau CS, Chia F, Harrison A, et al. APLAR rheumatoid arthritis treatment recommendations. Int $\mathrm{J}$ Rheum Dis. 2015;18:685-713.

9. The Royal Australian College of General Practitioners. Clinical guideline for the diagnosis and management of early rheumatoid arthritis. (2009). http://www.racgp.org.au/download/documents/ Guidelines/Musculoskeletal/racgp_ra_guideline. pdf. Accessed 22 June 2017.

10. Singh JA, Saag KG, Bridges SL Jr, et al. 2015 American College of Rheumatology guideline for the treatment of rheumatoid arthritis. Arthritis Rheumatol. 2016;68:1-26.

11. Smolen JS, Landewé R, Bijlsma J, et al. EULAR recommendations for the management of rheumatoid arthritis with synthetic and biological diseasemodifying antirheumatic drugs: 2016 update. Ann Rheum Dis. 2017;76:960-77.

12. Littlejohn G, Roberts L, Arnold M, et al. A multicenter, observational study shows high proportion of Australian rheumatoid arthritis patients have inadequate disease control. Int $\mathrm{J}$ Rheum Dis. 2013;16:532-8.

13. Montag K, Gingold M, Boers A, Littlejohn G. Disease-modifying anti-rheumatic drug usage, prescribing patterns and disease activity in rheumatoid arthritis patients in community-based practice. Intern Med J. 2011;41:450-5.

14. Alten R, Krüger $\mathrm{K}$, Rellecke J, et al. Examining patient preferences in the treatment of rheumatoid arthritis using a discrete-choice approach. Patient Prefer Adherence. 2016;10:2217-28.

15. Louder AM, Singh A, Saverno K, et al. Patient preferences regarding rheumatoid arthritis therapies: a conjoint analysis. Am Health Drug Benefits. 2016;9:84-93.

16. Fleischmann R, Cutolo M, Genovese MC, et al. Phase IIb dose-ranging study of the oral JAK inhibitor tofacitinib (CP-690,550) or adalimumab monotherapy versus placebo in patients with active rheumatoid arthritis with an inadequate response 
to disease-modifying antirheumatic drugs. Arthr Rheum. 2012;64:617-29.

17. Kremer JM, Cohen S, Wilkinson BE, et al. A phase IIb dose-ranging study of the oral JAK inhibitor tofacitinib (CP-690,550) versus placebo in combination with background methotrexate in patients with active rheumatoid arthritis and an inadequate response to methotrexate alone. Arthr Rheum. 2012;64:970-81.

18. Kremer JM, Bloom BJ, Breedveld FC, et al. The safety and efficacy of a JAK inhibitor in patients with active rheumatoid arthritis: results of a doubleblind, placebo-controlled phase IIa trial of three dosage levels of CP-690,550 versus placebo. Arthr Rheum. 2009;60:1895-905.

19. Tanaka Y, Takeuchi T, Yamanaka H, Nakamura $H$, Toyoizumi S, Zwillich S. Efficacy and safety of tofacitinib as monotherapy in Japanese patients with active rheumatoid arthritis: a 12-week, randomized, phase 2 study. Mod Rheumatol. 2015;25:514-21.

20. Tanaka Y, Suzuki M, Nakamura H, Toyoizumi S, Zwillich SH. Tofacitinib Study Investigators. Phase II study of tofacitinib (CP-690,550) combined with methotrexate in patients with rheumatoid arthritis and an inadequate response to methotrexate. Arthr Care Res (Hoboken). 2011;63:1150-8.

21. Burmester GR, Panaccione R, Gordon KB, McIlraith MJ, Lacerda AP. Adalimumab: long-term safety in 23,458 patients from global clinical trials in rheumatoid arthritis, juvenile idiopathic arthritis, ankylosing spondylitis, psoriatic arthritis, psoriasis and Crohn's disease. Ann Rheum Dis. 2013;72:517-24.

22. Fleischmann R, Kremer J, Cush J, et al. Placebocontrolled trial of tofacitinib monotherapy in rheumatoid arthritis. N Engl J Med. 2012;367:495-507.

23. Kremer J, Li Z-G, Hall S, et al. Tofacitinib in combination with nonbiologic disease-modifying antirheumatic drugs in patients with active rheumatoid arthritis: a randomized trial. Ann Intern Med. 2013;159:253-61.

24. Lee EB, Fleischmann R, Hall S, et al. Tofacitinib versus methotrexate in rheumatoid arthritis. N Engl J Med. 2014;370:2377-86.

25. van der Heijde D, Tanaka Y, Fleischmann R, et al. Tofacitinib (CP-690,550) in patients with rheumatoid arthritis receiving methotrexate: 12-month data from a 24-month phase III randomized radiographic study. Arthr Rheum. 2013;65:559-70.
26. van Vollenhoven RF, Fleischmann R, Cohen S, et al. Tofacitinib or adalimumab versus placebo in rheumatoid arthritis. N Engl J Med. 2012;367:508-19.

27. Yamanaka H, Tanaka Y, Takeuchi T, et al. Tofacitinib, an oral Janus kinase inhibitor, as monotherapy or with background methotrexate, in Japanese patients with rheumatoid arthritis: an open-label, long-term extension study. Arthr Res Ther. 2016;18:34.

28. Wollenhaupt J, Silverfield J, Lee EB, et al. Safety and efficacy of tofacitinib, an oral Janus kinase inhibitor, for the treatment of rheumatoid arthritis in open-label, long-term extension studies. J Rheumatol. $2014 ; 41: 837-52$.

29. Wollenhaupt J, Silverfield J, Lee EB, et al. Tofacitinib, an oral Janus kinase inhibitor, in the treatment of rheumatoid arthritis: safety and efficacy in open-label, long-term extension studies over 9 years. Arthr Rheumatol. 2017;69(Suppl 10):683-4.

30. Australian Government Therapeutic Goods Administration. Product Information: XELJANZ ${ }^{\circledR}$ tofacitinib (as citrate) tablet. (2017). https://www. ebs.tga.gov.au/ebs/picmi/picmirepository.nsf/pdf\% 3fOpenAgent\%26id\%3dCP-2015-PI-01192-1. Accessed 29 Nov 2017.

31. Smolen JS, Landewé R, Breedveld FC, et al. EULAR recommendations for the management of rheumatoid arthritis with synthetic and biological disease-modifying antirheumatic drugs: 2013 update. Ann Rheum Dis. 2014;73:492-509.

32. Strand V, Boers M, Idzerda L, et al. It's good to feel better but it's better to feel good and even better to feel good as soon as possible for as long as possible. Response criteria and the importance of change at OMERACT 10. J Rheumatol. 2011;38:1720-7.

33. Lubeck DP. Patient-reported outcomes and their role in the assessment of rheumatoid arthritis. Pharmacoeconomics. 2004;22:27-38.

34. Cella D, Yount S, Sorensen M, Chartash E, Sengupta $\mathrm{N}$, Grober J. Validation of the functional assessment of chronic illness therapy fatigue scale relative to other instrumentation in patients with rheumatoid arthritis. J Rheumatol. 2005;32:811-9.

35. Curtis JR, Lee EB, Martin G, et al. Analysis of nonmelanoma skin cancer across the tofacitinib rheumatoid arthritis clinical programme. Clin Exp Rheumatol. 2017;35:614-22.

36. Apalla Z, Lallas A, Sotiriou E, Lazaridou E, Ioannides D. Epidemiological trends in skin cancer. Dermatol Pract Concept. 2017;7:1-6. 
37. Perera E, Gnaneswaran N, Staines C, Win AK, Sinclair R. Incidence and prevalence of non-melanoma skin cancer in Australia: a systematic review. Australas J Dermatol. 2015;56:258-67.

38. Marcil I, Stern RS. Risk of developing a subsequent nonmelanoma skin cancer in patients with a history of nonmelanoma skin cancer: a critical review of the literature and meta-analysis. Arch Dermatol. 2000;136:1524-30.

39. Cohen SB, Tanaka Y, Mariette X, et al. Long-term safety of tofacitinib for the treatment of rheumatoid arthritis up to 8.5 years: integrated analysis of data from the global clinical trials. Ann Rheum Dis. 2017;76:1253-62.

40. Schulze-Koops H, Strand V, Nduaka C, et al. Analysis of haematological changes in tofacitinib-treated patients with rheumatoid arthritis across phase 3 and long-term extension studies. Rheumatol (Oxf). 2017;56:46-57.

41. Statista. Australia: Ethnic groups as of 2011. (2018). https://www.statista.com/statistics/260502/ethnicgroups-in-australia/. Accessed 4 Dec 2018. 